\title{
MIKROENKAPSULASI ASAM MEFENAMAT MENGGUNAKAN POLIMER HIDROKSI PROPIL METIL SELULOSA DAN NATRIUM ALGINAT DENGAN METODE GELAS IONIK
}

\author{
Sandra Aulia Mardikasari ${ }^{1}$, Suryani ${ }^{2}$, Nur Illiyyin Akib $^{2}$, Muhammad Handoyo Sahumena ${ }^{2}$, \\ Sri Hastuti ${ }^{2}$, Suci Ananda Putri ${ }^{1}$ \\ ${ }^{1}$ Fakultas Farmasi, Universitas Hasanuddin, Makassar, 90245, Indonesia \\ ${ }^{2}$ Fakultas Farmasi, Universitas Haluoleo, Kendari, 93232, Indonesia
}

Kata Kunci :

Mikroenkapsulasi, Asam Mefenamat, Natrium Alginat, HPMC, Gelasi lonik

\begin{abstract}
ABSTRAK
Asam mefenamat bersifat rentan terhadap cahaya maupun terhadap udara dan kelembaban. Selain itu asam mefenamat memiliki waktu paruh yang sempit, dapat menyebabkan peningkatan resiko gangguan gastrointestinal termasuk iritasi lambung pada penggunaan jangka panjang. Teknologi Mikroenkapsulasi merupakan proses penyalutan bahan aktif berupa cairan ataupun padatan dengan lapisan yang relatif tipis dengan ukuran partikel yang sangat kecil antara 0,2-5000 $\mu \mathrm{m}$. Tujuan penelitian ini untuk melakukan preparasi mikroenkapsulasi terhadap asam mefenamat menggunakan polimer Hidroksi Propil Metil Selulosa (HPMC) dan Natrium alginat dengan metode gelasi ionik lalu mengkarakterisasi hasil mikrokapsul yang diperoleh. Preparasi mikroenkapsulasi dilakukan dengan membandingkan konsentrasi polimer yang digunakan, dibuat dalam 3 formula. Parameter karakterisasi meliputi penetapan efisiensi penjerapan, distribusi ukuran partikel, bentuk partikel dan pengujian disolusi. Hasil karakterisasi menujukan mikroenkapsulasi Asam Mefenamat yang dihasilkan memiliki bentuk partikel yang spheris, dengan nilai efisiensi penjerapan terbesar yaitu 67,53\% untuk perbandingan HPMC dan natrium alginat masing-masing $4: 1$, sedangkan distribusi ukuran partikel bervariasi dengan ukuran terkecil yakni $1.105 \mu \mathrm{m}$, untuk hasil pengujian disolusi pada medium asam diperoleh konsentrasi pelepasan obat terbesar adalah $10,39 \mathrm{mg} / \mathrm{L}$ dan medium basa sebesar $74,456 \mathrm{mg} / \mathrm{mL}$. Penelitian Hasil penelitian ini menunjukkan bahwa asam mefenamat dapat dipreparasi dengan teknik mikroenkapsulasi sehingga dapat mengatasi beberapa kekurangan asam mefenamat.
\end{abstract}

\section{PENDAHULUAN}

Asam mefenamat merupakan analgetik yang termasuk dalam golongan obat Anti Inflamasi Non steroid (AINS). Asam mefenamat memiliki kelarutan dalam air yang rendah, dan berada dalam kelompok Biopharmaceutical Classification System (BCS) kelas II. Asam mefenamat memiliki waktu paruh yang pendek, dapat menyebabkan peningkatan resiko gangguan gastrointestinal termasuk iritasi lambung pada penggunaan jangka panjang (1). Asam mefenamat bersifat rentan terhadap cahaya maupun terhadap udara/ kelembaban (2). Untuk mengatasi kekurangan tersebut maka dapat dilakukan teknik mikroenkapsulasi terhadap asam mefenamat.

Mikroenkapsulasi merupakan suatu proses penyalutan bahan aktif berupa cairan maupun padatan dengan lapisan yang relatif tipis dengan ukuran partikel berkisar antara 2-5000 $\mu \mathrm{m}$ (3). Teknik mikroenkapsulasi biasa digunakan untuk meningkatkan stabilitas, mengurangi efek samping dan efek toksik obat, serta memperpanjang waktu pelepasan obat (4). Komponen utama dalam proses mikroenkapsulasi adalah polimer. Terdapat beberapa jenis polimer yang dapat digunakan, salah satunya adalah kombinasi Hidroksi Propil Metil Selulosa (HPMC) dengan antrium Alginat. HPMC merupakan polimer semi sintetik derivat selulosa yang biasa digunakan sebagai matriks dalam sediaan lepas lambat. HPMC mampu membentuk lapisan hidrogel yang kental pada sekeliling zat aktif setelah kontak dengan cairan pencernaan. HPMC merupakan polimer hidrofilik semi sintetik yang telah banyak digunakan sebagai pembawa untuk memperbaiki kelarutan, menjaga stabilitas, melindungi komponen yang tidak tahan terhadap lingkungan dan meningkatkan bioavaibilitas dari suatu zat (5). Polimer lain yang digunakan selain HPMC adalah natrium alginat. Natrium alginat memiliki kemampuan untuk melindungi komponen aktif dari faktor lingkungan yang dapat mempengaruhi stabilitas (6). Penelitian sebelumnya menunjukan bahwa mikroen-kapsulasi dapat dihasilkan menggunakan polimer HPMC dan natrium alginat (7).

Salah satu metode pembuatan mikroenkapsulasi yang dapat digunakan adalah metode gelasi ionik. Penggunaan metode gelasi ionik didasarkan pada kemampuan makromolekul untuk bertaut silang dengan adanya ion yang bermuatan berlawanan untuk membentuk hidrogel. Metode gelasi ionik dipilih karena memiliki sifat biokompatibilitas yang baik, mudah diaplikasikan, dan tidak membutuhkan pelarut organik dalam jumlah banyak sehingga biaya relatif murah (8).

Berdasarkan latar belakang tersebut, penelitian ini diharapkan dapat mengatasi beberapa kekurangan dari asam mefenamat dengan preparasi mikroenkapsulasi yang dilakukan menggunakan polimer HPMC dan Natrium alginat dengan metode gelasi ionik. Kemudian dilakukan karakterisasi berupa penetapan efisiensi penjerapan, penentuan ukuran partikel, bentuk partikel, seta pengujian disolusi. 


\section{METODE PENELITIAN}

\section{Mikroenkapsulasi Asam Mefenamat}

Formula acuan yang digunakan dalam penelitian ini berdasarkan penelitian yang telah dilakukan oleh (9). Mikroenkapsulasi asam mefenamat dibuat dalam tiga formula yang telah dimodifikasi. Ditimbang sebanyak 2 gram asam mefenamat, kemudan dilarutkan dengan larutan $\mathrm{NaOH}$ 0,1 N. Disiapkan polimer HPMC dan Natrium Alginat dengan perbandingan polimer 4:1, 1:4, dan 4:4 dilarutkan dalam aquadest sebanyak $50 \mathrm{~mL}$. Kemudian larutan asam mefenamat dan campuran polimer diaduk dengan magnetic stirrer sampai homogen. Setelah itu, campuran yang terbentuk diteteskan ke dalam larutan $\mathrm{CaCl}_{2} \quad 2 \%$ menggunakan jarum suntik 22-gauge dan didiamkan sampai 10 menit. Butiran yang dihasilkan disaring dan didekantasi kemudian dicuci berulang kali dengan aquades sampai $\mathrm{pH}$ netral dan bebas ion $\mathrm{Cl}$ kemudian dimasukan ke dalam oven untuk dikeringkan.

\section{Karakterisasi Mikroenkapsulasi Asam Mefenamat}

\section{Penetapan Efisiensi Penjerapan}

Penetapan efisiensi penjeratan zat aktif dilakukan dengan cara menimbang mikrokapsul $100 \mathrm{mg}$ dan dimasukan ke dalam gelas ukur $25 \mathrm{~mL}$ kemudian ditambahkan $10 \mathrm{~mL} \mathrm{NaOH}$. Campuran tersebut dimasukan ke dalam waterbath selama 30 menit untuk mengeluarkan zat aktif dari mikroenkapsulasi. Kemudian ditambahkan dapar fosfat $\mathrm{pH}$ 7,4 sampai $25 \mathrm{ml}(10)$. Efisiensi penjerapan dihitung dengan rumus :

$$
\mathrm{EE}=\frac{\text { bobot teranalisa }}{\text { bobot terkoreksi }} \times 100 \%
$$

\section{Distribusi Ukuran Partikel Mikroenkapsulasi}

Pengukuran partikel dilakukan dengan menggunakan mikroskop optik. Mikrokapsul yang akan diamati diletakkan di atas cawan petri dan selanjutnya ditentukan partikel yang diinginkan untuk memulai pengukuran diameter partikel menggunakan program pengukuran diameter partikel atau sejenisnya. Kemudian ditentukan keseluruhan diameter rata-rata dan dibuat kurva distribusi ukuran partikel (11)

\section{Pengamatan Bentuk Mikroenkapsulasi}

Mikrokaenkapsulasi diletakkan pada objek glass dan ditetesi dengan paraffin cair kemudian ditutup dengan cover glass dan diletakkan di bawah mikroskop. Atur sedemikian rupa sehingga diperoleh bentuk yang jelas (12).

\section{Pengujian Disolusi}

Uji disolusi menggunakan larutan dapar fosfat $\mathrm{pH}$ 7,4 dan larutan dapar asam klorida $\mathrm{pH}$ 1,2 sebagai medium disolusi dengan jumlah sebanyak $900 \mathrm{~mL}$. Metode yang digunakan yaitu metode dayung. Langkah pertama pembuatan dapar fosfat $\mathrm{pH} 7,4$ sebanyak 1 liter dengan mencampurkan $250 \mathrm{~mL}$ kalium dihidrogen fosfat $0,2 \mathrm{M}$ ditambahkan $39,1 \mathrm{~mL} \mathrm{NaOH}$ $0,2 \mathrm{~N}$ kemudian diencerkan dengan air bebas $\mathrm{CO}_{2}$ hingga 1 liter. Kemudian masukkan $900 \mathrm{~mL}$ larutan dapar fosfat $\mathrm{pH}$ 7,4 ke dalam labu disolusi. Langkah ketiga pasang alat disolusi, biarkan media disolusi hingga suhu $37^{\circ} \pm 0,5^{\circ}$ dengan pemanasan pada penangas air bertermostat. Langkah keempat masukan mikrokapsul ke dalam alat disolusi, alat dijalankan dengan kecepatan $50 \mathrm{rpm}$. Langkah kelima dilakukan pengambilan sampel $10 \mathrm{~mL}$, pada jam ke-1, $2,34,6$, dan 8 .

Posisi pengambilan sampel pada daerah pertengahan antara permukaan media disolusi dan bagian atas dari daun alat tidak kurang $1 \mathrm{~cm}$ dari dinding wadah. Setiap larutan percobaan yang diambil diganti kembali sehingga medium tetap berjumlah $900 \mathrm{~mL}$. Larutan $10 \mathrm{~mL}$ yang diambil diukur serapannya pada panjang gelombang maksimum dengan Spektrovotometer UV-Vis dan uji yang sama dilakukan dengan menggunakan buffer asam klorida $\mathrm{pH} 1,2$, perlakuan yang sama dilakukan pada masing-masing formula dan hitung kadar zat aktif yang terdisolusi (13)

\section{HASIL DAN PEMBAHASAN}

Preparasi mikroenkapsulasi pada penelitian ini menggunakan HPMC dan Natrium Alginat sebagai polimer dan menggunakan Asam Mefenamat sebagai zat aktif. Metode yang digunakan pada penelitian ini adalah gelasi ionik. Pada penelitian ini menggunakan polimer HPMC dan Natrium Alginat dengan perbandingan 4:1, 1:4, 4:4. Pembuatan mikrokapsul dengan menimbang asam mefenamat sebanyak 2 gram dilarutkan dengan larutan $\mathrm{NaOH}$, kemudian dilarutkan HPMC dan Natrium Alginat dalam wadah yang terpisah. Setelah kedua polimer larut kemudian campurkan polimer sampai homogen, setelah itu masukan zat aktif dan aduk sampai homogen. Setelah homogen teteskan dalam larutan $\mathrm{Cacl}_{2}$ menggunakan spoit $22 \mathrm{G}$, kemudian diamkan selama 10 menit, setelah itu saring lalu dimasukan ke dalam oven untuk dikeringkan. Hasil mikrokapsul dapat dilihat pada Gambar 1.

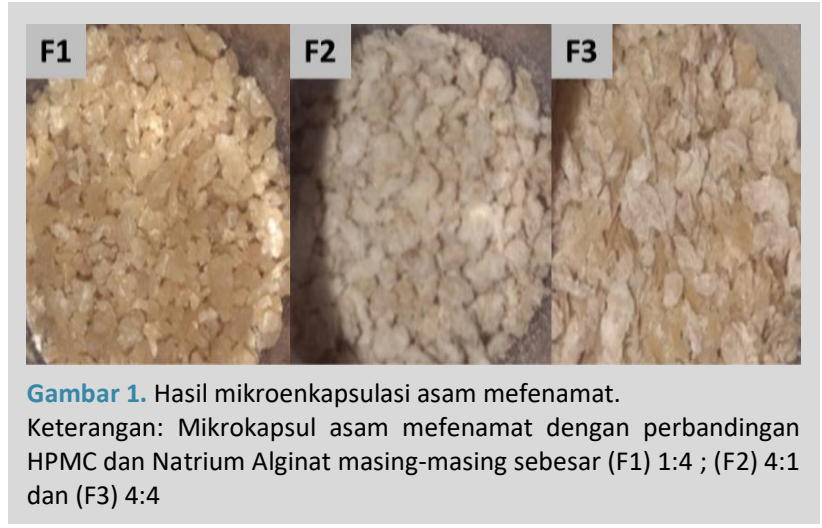

Mikroenkapsulasi dengan metode gelasi ionik didasarkan pada kemampuan makromolekul untuk bertaut silang dengan adanya ion yang berlawanan untuk membentuk hidrogel. Gelasi ionik meliputi pautan-silang dari polielektrolit dengan adanya counter ion multivalensi. Gelasi ionik sering diikuti pembentukan kompleks polielektrolit dengan perubahan muatan polielektrolit. Pembentukan kompleks ini menghasilkan suatu membran polielektrolit kompleks di permukaan partikel yang dapat meningkatkan kekuatan mekanik dari partikel (14).

Berdasarkan hasil perhitungan nilai efisiensi penjerapan yang paling besar diperoleh pada F2 dengan perbandingan HPMC dan natrium Alginat sebesar 4;1 yakni 67,53\%, kemudian F3 yakni $61,66 \%$ dan terakhir F1 yakni $48,76 \%$. Nilai F1 memiliki nilai penjerapan lebih kecil bila dibandingkan dengan F2 dan F3. Semakin besar konsentrasi natrium alginat menyebabkan semakin rapatnya densitas bahan penyalut sehingga menyebabkan za aktif sukar masuk sehingga kadarnya menjadi lebih sedikit. Semakin besar konsentrasi alginat maka akan semakin banyak ikatan antara gugus karboksilat dari alginat dengan ion $\mathrm{Ca}^{2+}$. Semakin banyaknya ikatan maka struktur ikatan akan semakin rumit yang mengakibatkan smakin kecil pori yang terbentuk sehigga terjadi penurunan porositas (15).

Distribusi ukuran partikel merupakan evaluasi fisik pada mikroenkapsulasi untuk mengetahui diameter rata-rata partikel. Alat ukur yang digunakan yakni dengan mikroskop optik. Berdasarkan hasil pengukuran didapatkan hasil F1 
sebesar $1.105 \mu \mathrm{m}, \mathrm{F} 2$ sebesar $1.482 \mu \mathrm{m}$ dan F3 sebesar 1.405 $\mu \mathrm{m}$. Hasil dari distribusi ukuran partikel tersebut masuk dalam range metode gelsi ionik yaitu $2-5000 \mu$ m (16). Hasil distribusi ukuran partikel dapat dilihat pada Gambar 2.

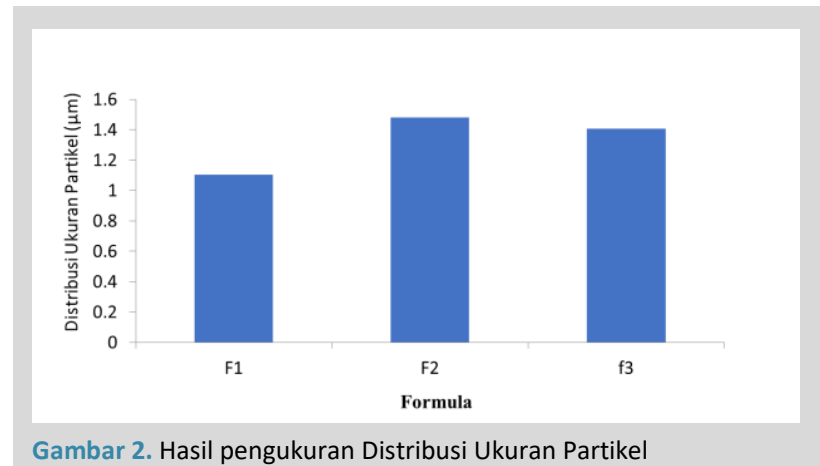

Pengamatan sifat mikroskopis dari mikrokapsul asam mefenamat dilakukan dengan menggunakan mikroskop optik. Hasil yang diperoleh menunjukan bahwa mikrokapsul yang dihasilkan berbentuk spheris. Hal ini menunjukkan bahwa obat tersalut dengan baik, zat aktif tersebar merata di dalam polimer dan tidak ada rongga didalamnya sehingga pelepasan obat dapat lebih lambat. Terdapat beberapa fakor yang mempengaruhi bentuk dari partikel antara lain konsentrasi polimer yang digunakan, jarak antar jarum suntik dan larutan pembentuk mikrokapsul, perbedaan tekanan saat pembentukan mikrokapsul melalui syringe, serta tinggi rendahnya posisi syringe yang digunakan dalam proses pembuatan (17). Hasil yang diperoleh dapat dilihat pada Gambar 3.

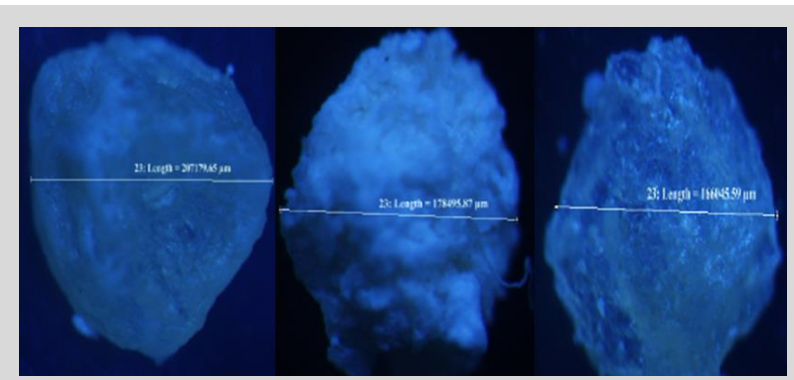

Gambar 3. Bentuk Partikel

Uji disolusi mikroenkapsulasi asam mefenamat dilakukan menggunakan alat disolusi tipe II (metode dayung). Medium uji yang digunakan yaitu larutan $\mathrm{pH} 1,2$ sebagai simulasi $\mathrm{pH}$ lambung dan medium dapar fosfat $\mathrm{pH}$ 7,4 sebagai simulasi $\mathrm{pH}$ usus. Medium yang digunakan sebanyak $900 \mathrm{~mL}$ dengan kecepatan putaran 50 rpm selama 6 jam dengan interval waktu 10, 20, 30, 45, 60, 120, 240 dan 360 menit. Pengambilan larutan disolusi sebanyak 5,0 mL dan volume yang hilang diganti dengan media disolusi yang sama yaitu dapar $\mathrm{pH} 7,4$.

Pelepasan mikroenkapsulasi asam mefenamat di $\mathrm{pH}$ 1,2 dapat dilihat pada Gambar 4. Dari grafik tersebut terlihat pelepasan obat di menit ke-360 untuk F1 mampu melepaskan zat aktif sebanyak $10.39 \mathrm{mg} / \mathrm{L}, \mathrm{F} 2$ sebanyak $8.427 \mathrm{mg} / \mathrm{L}$ sedangkan F3 sebanyak $6.607 \mathrm{mg} / \mathrm{L}$. Hal ini menunjukkan bahwa terjadi pelepasan zat aktif yakni asam mefenamat dari mikrokapsul di medium asam. Pelepasan zat aktif ini dapat terjadi karena polimer penyalut yang digunakan yakni HPMC berpotensi larut pada medium asam sehingga membuat polimer dapat melepaskan obat yang ada di dalamnya, tetapi jumlahnya tidak besar karena terdapat polimer lainnya yakni natrum alginat yang akan menahan lepasnya zat aktif karena natrium alginat pada $\mathrm{pH} \mathrm{1,2} \mathrm{akan} \mathrm{menjadi} \mathrm{asam} \mathrm{alginat} \mathrm{yang}$ bersifat hidrofob dan jika berada pada $\mathrm{pH}<3,5$ akan mengendap sehingga menjadi sukar larut (17).

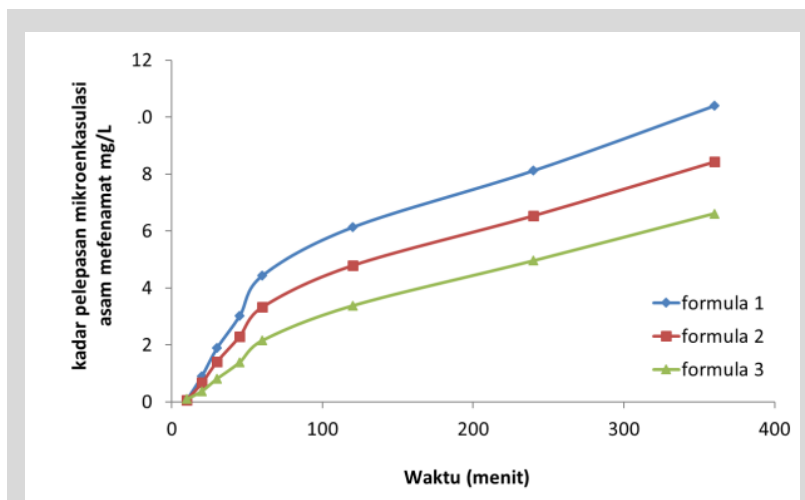

Gambar 4. Profil disolusi pada pH 1,2

Pelepasan mikroenkapsulasi asam mefenamat di $\mathrm{pH} 7,4$ dapat dilihat pada Gambar 5. Dari grafik terlihat pelepasan obat pada menit ke-360 untuk F1 sebesar $74.456 \mathrm{mg} / \mathrm{mL}$, F2 sebesar $55.596 \mathrm{mg} / \mathrm{mL}$, dan F3 sebesar $50.233 \mathrm{mg} / \mathrm{mL}$. Jumlah obat yang dilepaskan cukup besar dibandingkan dengan pelepasan pada medium asam $\mathrm{pH}$ 1,2. Hal ini dikarenakan oleh polimer yang digunakan yakni HPMC dan Natrium Alginat mudah larut pada kondisi tersebut sehingga zat aktif dapat keluar dari cangkang mikrokapsul. HPMC stabil pada pH 3-11 dan Natrium alginat di pH 4-10(18). Dari data diatas, jumlah obat yang dilepaskan oleh F1 lebih besar jika dibandingkan dengan F2 dan F3, hal ini dikarenakan F1 memiliki jumlah HPMC lebih banyak dari pada jumlah Natrium Alginat, sehingga zat aktif lebih mudah berdifusi keluar. Jumlah natrium alginat yang digunakan mempengaruhi pelepasan obat dan kekuatan jaringan matriks mikrokapsul. Natrium alginat membentuk matriks dengan ikatan taut silang ketika alginat kontak dengan kation divalen (seperti ion kalsium pada larutan $\mathrm{CaCl}_{2}$ ) secara seketika menginduksi polimerisasi ion pada antarmuka alginat melalui ikatan kation dengan unit asam guluronat menghasilkan pautan silang tiga dimensi dengan struktur eggbox sehingga terjadi pembentukan mikrokapsul polikationik. Sedangkan pada F3 jumlah polimer yang digunakan lebih banyak dibandingkan F1 dan F2, sehingga zat aktif yang keluar lebih sedikit. Semakin besar jumlah polimer yang digunakan maka pelepasan zat aktif dalam mikrokapsul juga akan lambat karena semakin tebalnya dinding mikrokapsul (19).

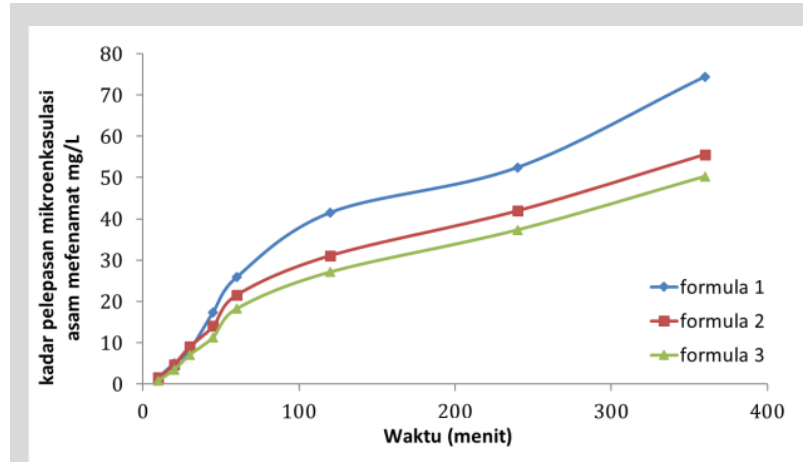

Gambar 5. Profil disolusi pada $\mathrm{pH} 7,4$

Pelepasan asam mefenamat dari polimer HPMC - Natrium alginat dimulai ketika polimer kontak langsung dengan medium disolusi, kemudian terjadi penetrasi cairan ke dalam polimer, sehingga polimer akan mengembang dan membentuk gel. Lapisan gel berfungsi sebagai penghalang di sekeliling polimer yang mengontrol pelepasan obat dari dalam polimer. Semakin tebal lapisan gel yang menghalangi semakin sulit obat berdifusi keluar polimer. Oleh karena itu waktu yang dibutuhkan untuk melepaskan sejumlah obat menjadi lebih lama (20). 


\section{KESIMPULAN}

Dari penelitian yang telah dilakukan dapat disimpulkan bahwa mikroenkapsulasi asam mefenamat dapat dipreparasi menggunakan polimer natrium alginat dan HPMC dengan menggunakan metode gelasi ionik. Jumlah polimer dan perbandingan polimer mempengaruhi penjerapan dan pelepasn obat dari matriks mikrokapsul. Penelitian ini dapat dikembangkan untuk optimasi sediaan lepas lambat.

\section{DAFTAR PUSTAKA}

1. Patel, M.J., Patel,N.M., Patel, R.B., Dan Patel R,P. (2010) Formulation And Evaluation Of Self-Microemulsifying Drug Delivery System Of Lovastatis, Asian. J. Pharm. Vol 5(6):266-275.

2. Indrawati, T., dan Sari, N.K. (2010) Stabilitas Kap;Et Asam Mefenamat Dengan Suhu Dan Kelembapan Ruang Penyimpanan yang Berbeda. Makara Kesehatan. Vol. 14(2):75-80.

3. Jyothi, N.V.N.,P. Muthu. P.,Suhas, N.S.,K Surya, P., P.P Seetha, R., dan G. Y Srawan. (2010) Microencapsulation Techniques, Faktor Influenching Encapsulation Efficiecy. Journal Of Microencaptulation. Vol 27. No. 3.

4. Firdyawati. (2014) Skripsi: Formulasi Mikropartikel Teofilin Menggunakan PenyalutKitosan-Alginat Yang Dipaut Silang dengan Natrium Tripolifosfat.

5. Launer, C. Dan Jenifer, D. (2000) Review Article, Improving Drug Solubility For Oral Dlivery Using Dispersions. European Journal Of Pharmaucetics And Biopharmaucetics, 50,47-60.

6. Kuen Yong., David J. Mooney. (2012) Alginate: Properties and biomedical applications. Elsevier

7. Chowdary And Madhavi. (2011) Preparation And Evaluation Of HpmcAlginate Mucoadhesive Microcapsules Of Diclofenac For Controlled Release, IJPSR. Vol. 2(11): 2801-2805

8. Handayani, I. (2008) Karakterisasi dan Profil Disolusi Atenol Dari Matriks Kompleks Poliion Kitosan-Natrium Alginat. Fakultas Matematika Dan Ilmu Pengetahuan Alam Departemen Farmasi. Universitas Indonesia Depok
9. Trisnawati, A.R., dan Sari, E.C., 2014. Enkapsulasi Pirazinamid Menggunakan Alginat-Kitosan dengan Variasi Konsentrasi Penambahan Surfaktan Tween 80. UNESA Journal of Chemistry. Vol.3 (3).

10. Rao, A,P., dkk, 2011. Preparation and Evaluation Of Muchoadesive Microcapsules of Ibu Profen For Controllled release. International Research Journal Of Pharmacy. Vol 2(5): 257-260.

11. Utama, D.A., Esti, H., dan Dewi, M.H., 2013. Pengaruh Kecepatan Pengadukan Terhadap Karakteristik Fisik Mikrosfer Ovalbumin-Alginat Dengan Metode Aerosolisasi. PharmaScientia. Vol.2(2).

12. Noviza1 D , Tita H dan Ade A.R, 2013, Mikroenkapsulasi Metformin Hidroklorida Dengan Penyalut Etilsellulosa Menggunakan Metoda Penguapan Pelarut, Jurnal Sains dan Teknologi Farmasi, Vol.18(1) :ISSN : 1410-0177.

13. Kurniawan, R., Dan Deni R., 2015. Mikroenkapsulasi Controlled Release Lansoprazol Dengan Kombinasi Hydroxy Propil Methyl Cellulose Phathalate Dan Natrium Alginat Secara Gelasi Iontropik. Jurnal Ilmu Kefarmasian Indonesia. Vol. 14(1): ISSN 1693-1381.

14. Srifiana, Yudi. 2014. "Mikroenkapsulasi Ketoprofen dengan Metode Koaservasi Menggunakan Pragelatinisasi Pati Singkong dan Metode Semprot Kering Menggunakan Pragelatinisasi Pati". Skripsi. Depok: Fakultas Farmasi Program Studi Magister Ilmu Kefarmasian. Universitas Indonesia

15. Findia, P., Sari Edi Cahyaningrum. (2014) Enkapsulasi Pirazinamid Menggunakan Alginate Dan Kitosan. UNESA Journal OfChemistry. Vol 3(3).

16. Kasih, N. (2014) Skripsi. Formulasi Dan Karakterisasi Mikropartikel Ektrak Etanol 50\% Kult Buah Manggis (Garcinia Mangostana L.) Dengan Metode Semprot Kering (Spray Drying).

17. Balla, A., Dr. Shivanand Kalyanappa., Haarika Maddineni., Ashvini H.M. (2014) Formulation And In Vitro Evaluation Of Microparticle Carrier Containing Mefenamic Aci, World Journal Of Pharmacy And Pharmaceutical Sciences. Vol. 3(3): ISSN 2278 - 4357. Bogor: FMIPA UI, 2008

18. Rowe, R.C., Paul, J.S., dan Marian, E.Q., 2009, Handbook pf Pharmaceutical Excipients Sixth Editio, Chicago, London: Pharmaceutical Press

19. Bolourtchian, N., Karimi, K., Aboofazeli, R., 2005. Preparation and characterization of ibuprofen microspheres. Journal of Microencapsulation. Vol. 22 :529-538.

20. Herdini, Latifah, K.D., dan Purwantiningsih, S. (2010). Disolusi Mikroenkapsulasi Kurkumin Tersalut Gel Kitosan-Alginat-Glutaraldehida Makara Sains. Vol. 14 (1) 